\title{
Low BRAF V600 mutation prevalence in primary skin nodular melanoma in Indonesia: a real-time PCR detection among Javanese patients
}

Hanggoro Tri Rinonce ${ }^{1 *}$, Rovi Panji Mustiko Aji ${ }^{1}$, Ni'mah Hayati ${ }^{1}$, Maria Fransiska Pudjohartono ${ }^{1}$, Bidari Kameswari ${ }^{2}$ and Irianiwati $^{1}$

From 3rd International Symposium on Congenital Anomaly and Developmental Biology 2019

Yogyakarta, Indonesia. 8-9 August 2019

\begin{abstract}
Background: Cutaneous melanoma is a rare, aggressive skin malignancy with a high mortality rate. Although only contributing $7.6 \%$ of the cases worldwide, Asia is responsible for $18.6 \%$ of deaths from cutaneous melanoma. BRAF V600 mutation presents a potential prognostic predictor in melanoma. Unfortunately, studies on that mutation in melanoma, particularly nodular subtype, in Indonesia are still scarce. This research aimed to investigate the prevalence of BRAF V600 mutation in primary skin nodular melanoma in Yogyakarta and Central Java, Indonesia. Its association with clinicopathological parameters was also analyzed.

Methods: Forty paraffin-embedded tissue samples from primary skin nodular melanoma cases in 2011-2018 were collected from the two biggest referral hospitals in Yogyakarta and Central Java, Indonesia. The BRAF V600 mutation status was assessed using qualitative real-time PCR and its associations with age, sex, anatomic location, lymph node metastasis, tumor thickness, ulceration, mitotic index, necrosis, lymphovascular invasion, and tumor-infiltrating lymphocytes were analyzed.
\end{abstract}

Results: BRAF V600 mutations were found in $4(10 \%)$ samples. These mutations were significantly associated with the central (non-extremity) region $(p=0.013)$ and presence of lymphovascular invasion $(p=0.005)$. However, it was not associated with any other variables analyzed in this study.

Conclusion: The prevalence of BRAF V600 mutation in Indonesian primary skin nodular melanoma cases is low and significantly associated with anatomic location and lymphovascular invasion. It is lower than prevalences in other Asian populations as well as in Caucasian populations and suggests that melanoma cases in Javanese people may have distinct clinicopathological characteristics from other Asian ethnicities.

Keywords: Nodular melanoma, Skin tumor, BRAF, BRAF V600 mutation, Indonesia

\footnotetext{
* Correspondence: hanggoro_rinonce@ugm.ac.id

'Department of Anatomical Pathology, Faculty of Medicine, Public Health,

and Nursing, Universitas Gadjah Mada/ Dr. Sardjito Hospital, Radiopoetro

Building, 4th Floor, Farmako Street, Sekip Utara, Sinduadi, Mlati, Sleman,

Yogyakarta 55281, Indonesia

Full list of author information is available at the end of the article
}

(c) The Author(s). 2019 Open Access This article is distributed under the terms of the Creative Commons Attribution 4.0 International License (http://creativecommons.org/licenses/by/4.0/), which permits unrestricted use, distribution, and reproduction in any medium, provided you give appropriate credit to the original author(s) and the source, provide a link to the Creative Commons license, and indicate if changes were made. The Creative Commons Public Domain Dedication waiver (http://creativecommons.org/publicdomain/zero/1.0/) applies to the data made available in this article, unless otherwise stated. 


\section{Background}

Cutaneous melanoma is a rare, aggressive skin malignancy with a high mortality rate. The incidence varies among countries, with lower incidence in Asian populations compared to Caucasian populations. Estimates report $0.43-0.48$ new cases per 100.000 people in East and South-East Asia, as compared to 12.6-18.8 new cases per 100.000 people in North America and Europe annually [1]. Although only contributing $7.6 \%$ to the total global incidence, Asia is responsible for $18.6 \%$ of the world mortality from melanoma. This shows that despite its low incidence, melanoma cases in Asia have poor prognoses and are often fatal.

Various clinicopathologic factors affect the outcomes of melanoma patients. Patients with younger age, female gender, extremity location, and no nodal nor distant metastases tend to have better prognoses [2]. Histopathologic factors, such as tumor subtype, thickness, ulceration, mitotic index, lymphovascular invasion, and tumor-infiltrating lymphocytes (TILs), also determine prognosis. Certain genetic mutations can affect melanoma patients' prognoses, such as the BRAF gene mutation.

The BRAF gene mutation is known as one of the most common mutations in melanoma, with V600 as the most common site of mutation [3]. The discovery of the BRAF V600 mutation opened opportunities for new modes of treatment and prognostic prediction. This prognostic role can be studied through the association between this mutation and the previously identified clinicopathologic factors. However, current evidence on the association between the BRAF mutation and clinicopathologic factors is still sparse and conflicting [2].

The application of these researches to Asian populations is further complicated by the distinct behavior of melanoma in different races. Previous studies suggest that melanoma among Asian patients have different clinicopathologic characteristics from Caucasian patients, especially in subtype frequencies, risk factors, and mutation patterns [4]. The BRAF V600 mutation is found in 40-60\% Caucasian patients [3], as opposed to 11.9 to 41.8\% Asian patients [5-9]. The current bulk of evidence on BRAF V600 mutations has been obtained from Caucasian patients, deeming it possibly unsuitable for Asian populations.

Indonesia is no exception in this respect, as it also suffers from under-reporting and lack of data on melanoma cases. Due to the scarcity of data, even the most common subtype of melanoma in Indonesia is still questionable. Three different studies reported different subtypes as the most common subtype. One study reported acral lentiginous melanoma as the most common subtype [10], while the Global Burden of Disease study found the superficial spreading subtype [4]. Yet a recent study reported nodular melanoma as the predominant subtype in Yogyakarta, Indonesia [11]. These contradictory results emphasize the lack of data on melanoma in Indonesia. Regarding BRAF mutation studies, only one article has studied the BRAF V600 mutation prevalence among acral lentiginous melanoma in Indonesia so far [12]. No mutation studies have been done on nodular melanoma in Indonesia at all.

Being a relatively uncommon subtype in Asia, nodular melanoma has not been studied much in Asian populations. Despite its low frequency, nodular melanoma is an important contributor to melanoma deaths. A study from Australia reported that although nodular melanomas represented $14 \%$ of the invasive melanomas, they were responsible for $43 \%$ of the deaths [13]. This dire prognosis further reinforces the necessity for research on nodular melanomas.

Given the lack of evidence for Indonesian populations, further research is needed to elucidate the prevalence of the BRAF V600 mutation and its associations with clinicopathologic parameters among nodular melanoma cases in Indonesia. This research aimed to investigate the prevalence of BRAF V600 mutation in primary skin nodular melanoma in Yogyakarta and Central Java, Indonesia. Its associations with clinicopathological parameters were also analyzed.

\section{Materials and methods}

This retrospective cross-sectional study was conducted in the Department of Anatomical Pathology Dr. Sardjito Hospital, Yogyakarta and dr. Soeradji Tirtonegoro Hospital, Central Java, Indonesia. Both hospitals were the biggest referral hospitals in Yogyakarta Province and Central Java Province located in Java Island, Indonesia. Forty paraffin-embedded tissue samples from primary skin nodular melanoma cases in 2011-2018 were collected and analyzed. All melanoma patients were Javanese, one of the ethnic groups in Indonesia.

The presence of BRAF V600 mutation was assessed using qualitative real-time PCR. Four slices ( $5 \mu \mathrm{m}$ thick) of formalin-fixed paraffin-embedded (FFPE) tumor tissues were used for the source of DNA. After deparaffinization and hematoxylin-eosin staining, slides were observed under a microscope and the tumor-containing areas were scraped into tubes for DNA extraction. The DNA extraction was done using the GeneAll ${ }^{\circ}$ ExgeneTM DNA Extraction Kit (GeneAll Biotechnology, Seoul, Korea) according to the protocol provided by the producer. The obtained DNA was amplified through real-time PCR using the AmoyDx ${ }^{\circ}$ BRAF V600 Mutations Detection Kit (AmoyDx, Xiamen, Cina). This kit may detect all BRAF V600 mutation types including V600E, V600K, V600D, and V600R.

Clinicopathologic data were obtained from registry records at the Department of Anatomical Pathology Dr. Sardjito and dr. Soeradji Tirtonegoro Hospitals. The data 
collected consisted of age, sex, anatomic location, lymph node metastasis, tumor thickness, ulceration, mitotic index, necrosis, lymphovascular invasion, and TILs. Anatomic location was classified into extremity and central (trunk, head, and neck) location.

Hematoxylin-eosin stained slides were observed microscopically for lymph node metastasis, tumor thickness, ulceration, necrosis, lymphovascular invasion, and TILs. Presence or absence of lymph node metastasis was assessed by examining lymph node biopsy specimens for tumor cells. Tumor thickness was measured from the granular layer to the deepest level of the tumor, and subsequently classified as $\leq 4 \mathrm{~mm}$ or $>4 \mathrm{~mm}$. Presence of ulceration was defined as thinning of the epidermis to full-thickness epidermal defect. Necrosis was classified into present or absent, with presence of necrosis defined as the presence of an area of necrotic cells covering at least $1 / 4$ high power field $\left(0.07 \mathrm{~mm}^{2}\right)$. Finding tumor cells identical to the cutaneous melanoma cells in lymph and or blood vessels surrounding the tumor was categorized as the presence of lymphovascular invasion. TILs were defined as lymphocytes migrating from the blood vessels to the peritumoral and intratumoral stroma [14] and classified into absent or present which comprised the brisk and non-brisk category.

For the immunohistochemistry study, paraffin blocks were sliced as thick as $5 \mu \mathrm{m}$, deparaffinized, and rehydrated. Subsequently, antigen retrieval was performed using Ventana Ultra Cell Conditioner 1 solution (Ventana Medical Systems, Tucson, AZ, USA) under pH 8-9 in 64 min on $95^{\circ} \mathrm{C}$. Slides were incubated in $3 \%$ hydrogen peroxide for $5 \mathrm{~min}$, diluted primary antibody for $30 \mathrm{~min}$, labeled polymer, HRP for $30 \mathrm{~min}$, diaminobenzidine for 5 $\mathrm{min}$, and counterstained using hematoxylin for $15 \mathrm{~min}$. Incubation was performed in room temperature. Within the incubation process, slides were washed by tris-buffered saline. Slides were covered by a coverslip. Antibody used in this study was monoclonal Ki67 antibody (Abcam, Cambridge, MA, USA). The mitotic index was calculated as the percentage of positively stained nuclei per 1000 tumor cells and further classified as $<20 \%$ and $\geq 20 \%$.

The association between BRAF mutation status and clinicopathologic parameters (age, sex, anatomic location, lymph node metastasis, tumor thickness, ulceration, mitotic index, necrosis, lymphovascular invasion, tumor-infiltrating lymphocytes) was analyzed by the Fisher's exact test for categorical variables, and the Mann-Whitney test for continuous variables.

\section{Results}

The patients' age ranged from 21 to 80 years, with an average of 62.35 years of age. Sixteen (40\%) patients were male and twenty-four (60\%) patients were female. Thirty-three patients $(82.5 \%)$ had tumors on extremities, while 7 (17.5\%) had tumors on the trunk or head and neck (centrally located). Out of the forty samples, BRAF V600 mutations were found in $4(10 \%)$ samples. Among them, three had central lesions while only one had the lesion on an extremity. The association between mutation status and the clinicopathologic parameters is shown in Table 1.

Positive BRAF V600 mutation was significantly associated with central anatomic location $(p=0.013)$ and lymphovascular invasion $(p=0.005)$. There were no

Table 1 The association between BRAF mutation status and clinicopathologic parameters

\begin{tabular}{|c|c|c|c|}
\hline & BRAF $(+)$ & $\operatorname{BRAF}(-)$ & $p$ value $^{b}$ \\
\hline$\overline{\text { Age, mean } \pm S D^{a}}$ & $56.25 \pm 24.55$ & $63.03 \pm 12.03$ & 0.926 \\
\hline \multicolumn{4}{|l|}{ Age category, n (\%) } \\
\hline$<65$ years & $3(7.5)$ & $23(57.5)$ & \multirow[t]{2}{*}{1.000} \\
\hline$>65$ years & $1(2.5)$ & $13(32.5)$ & \\
\hline \multicolumn{4}{|l|}{ Sex, n (\%) } \\
\hline Male & $2(5.0)$ & $14(35.0)$ & \multirow[t]{2}{*}{1.000} \\
\hline Female & $2(5.0)$ & $22(55.0)$ & \\
\hline \multicolumn{4}{|l|}{ Anatomic location, n (\%) } \\
\hline Extremity & $1(2.5)$ & $32(80.0)$ & \multirow[t]{2}{*}{0.013} \\
\hline Central & $3(7.5)$ & $4(10.0)$ & \\
\hline \multicolumn{4}{|c|}{ Lymph node metastasis, n (\%) } \\
\hline Present & $2(5.0)$ & $15(37.5)$ & \multirow[t]{2}{*}{1.000} \\
\hline Absent & $2(5.0)$ & $21(52.5)$ & \\
\hline \multicolumn{4}{|l|}{ Tumor thickness, n (\%) } \\
\hline$\leq 4 \mathrm{~mm}$ & $1(2.5)$ & $5(12.5)$ & \multirow[t]{2}{*}{0.493} \\
\hline$>4 \mathrm{~mm}$ & $3(7.5)$ & $31(77.5)$ & \\
\hline \multicolumn{4}{|l|}{ Ulceration, n (\%) } \\
\hline Present & $2(5.0)$ & $21(52.5)$ & \multirow[t]{2}{*}{1.000} \\
\hline Absent & $2(5.0)$ & $15(37.5)$ & \\
\hline Mitotic index, mean $\pm \mathrm{SD}^{\mathrm{a}}$ & $28.25 \pm 17.60$ & $22.11 \pm 17.67$ & 0.487 \\
\hline \multicolumn{4}{|l|}{ Mitotic index category, n (\%) } \\
\hline$\geq 20 \%$ & $3(7.5)$ & $16(40.0)$ & \multirow[t]{2}{*}{0.331} \\
\hline$<20 \%$ & $1(2.5)$ & $20(50.0)$ & \\
\hline \multicolumn{4}{|l|}{ Necrosis, n (\%) } \\
\hline Present & $2(5.0)$ & $26(65.0)$ & \multirow[t]{2}{*}{0.570} \\
\hline Absent & $2(5.0)$ & $10(25.0)$ & \\
\hline \multicolumn{4}{|c|}{ Lymphovascular invasion, n (\%) } \\
\hline Present & $4(10.0)$ & $8(20.0)$ & \multirow[t]{2}{*}{0.005} \\
\hline Absent & $0(0.0)$ & $28(70.0)$ & \\
\hline \multicolumn{4}{|c|}{ Tumor-infiltrating lymphocytes, n (\%) } \\
\hline Present & $4(10.0)$ & $24(60.0)$ & \multirow[t]{2}{*}{0.297} \\
\hline Absent & $0(0.0)$ & $12(30.0)$ & \\
\hline
\end{tabular}

${ }^{\mathrm{a}} \mathrm{SD}=$ standard deviation

${ }^{\mathrm{b}} P$ value $<0.05$ was considered significant. Significant values are indicated in bold 
significant associations between BRAF mutation status and age, sex, lymph node metastasis, tumor thickness, ulceration, mitotic index, necrosis, nor tumor-infiltrating lymphocytes.

\section{Discussion}

In this study, we studied the prevalence of BRAF V600 mutation in primary skin nodular melanoma and its association with clinicopathological parameters. The BRAF V600 mutation was found in 4 patients, yielding a prevalence of $10 \%$ among nodular melanoma cases. There is little comparable data in Asia due to the limited studies on nodular melanomas. A study in Japan reported that $50 \%$ of nodular melanoma cases had the BRAF V600 mutation [6], while another research in Turkey stated the percentage at $29.4 \%$ [15].

When compared to the previous studies for all melanoma subtypes in Asia, the prevalence of BRAF V600 mutation in this study was still lower than other Asian countries. Asian melanoma cases are dominated by the acral lentiginous subtype [4], while nodular melanoma was the most common subtype in Yogyakarta and Central Java, Indonesia [11]. This subtype pattern resembled two studies, in Mexico and Germany respectively, which also found nodular melanoma as the most common subtype $[16,17]$. Nodular melanomas are known to have BRAF V600 mutation rates approximately twice higher than acral lentiginous melanomas [18]. However, the prevalence found in this study was lower than the previous findings for all melanoma subtypes in Asia (11.9 to 41.8\%). This outcome further reaffirms that Indonesian melanoma cases do have a significantly lower BRAF V600 prevalence compared to Asia in general.

Researches from nodular melanoma cases outside Asia reported higher prevalence results compared to this study. Studies from Caucasian populations, such as Australia and the United States, Germany, and Norway, report prevalence of BRAF V600 mutations in nodular melanomas at $22.37 \%$ [19], 37.7\% [17], and 40.84\% [20], respectively. A study in Mexico reported the prevalence of the mutation at 29.09\% in nodular melanomas [16]. In Brazil, 80\% nodular melanomas had the BRAF V600 mutation [21]. A Nigerian study yielded a prevalence of $11 \%$ in all melanoma samples [22], a closer number to our results. However, the detection of BRAF V600 mutation in this Nigerian study was done using immunohistochemistry, which is less sensitive compared to PCR studies. Hence, the prevalence when measured using the PCR technique would most likely be higher still in African populations.

The unusual subtype distribution and mutation pattern may indicate that melanoma cases in Javanese ethnic indeed present an anomaly among other Asian populations. Genetic variations between the different ethnicities may influence the prevalence of certain mutations [23], which may explain the wide variation of BRAF V600 mutation rates in Asia. The current evidence from Asia mostly studied East Asia populations, with nearly no data from South-East Asia regions. Melanomas with wild-type BRAF likely have mutations in the upstream proteins of the MAPK pathway, such as NRAS or KIT [24]. The low BRAF mutations prevalence in this study should prompt further studies to investigate upstream mutations in the MAPK pathway in South-East Asia, including Indonesia.

Unique combinations of underlying pathophysiological factors may also affect the BRAF V600 mutation prevalence. Sun exposure is one of the best-known factors in melanoma pathogenesis. Ultraviolet radiation can induce damage to DNA, including the BRAF gene [24]. However, BRAF mutation more frequently appears in melanomas in locations without chronic sun damage. Melanoma cases in Asian patients tend to appear in areas that are rarely sunexposed, giving rise to the conjecture that sun exposure does not play a major role in Asian melanomas [4]. In our study, 33 out of 40 patients had lesions on the extremities which were more exposed to the sun compared to central locations. Considering that central locations are associated with BRAF mutations both in previous studies [18] and this study, the low percentage of centrally located lesions may contribute to the lower prevalence of the BRAF V600 mutation.

Differences in population characteristics and research methods may also have contributed to the lower prevalence of BRAF V600 mutation. The older population in this study (with $65 \%$ participants above 65 years of age) may have influenced the mutation prevalence, as BRAF V600 mutation is associated with younger patients [25]. More advanced methods, such as next-generation sequencing, would have enhanced the sensitivity of BRAF V600 mutation detection [26] and enabled more indepth study of specific mutation types (such as V600E, V600K, V600D, and V600R) [27].

BRAF V600 mutation showed associations with clinicopathologic characteristics, namely central location and the presence of lymphovascular invasion. Previous melanoma studies report that BRAF V600 mutations were found approximately twice more often in the trunk compared to non-trunk locations [18]. Central (trunk, head, and neck) areas receive less sun exposure and chronic sun damage, which is associated with higher rates of BRAF mutation in various studies. A study in Boston also reported higher rates of lymphovascular invasion with BRAF mutation [28]. Lymphovascular invasion happens earlier and is a more sensitive examination than lymph node metastasis, hence explaining the association with lymphovascular invasion but not lymph node metastasis. No significant associations were found between the BRAF V600 mutation with age, sex, lymph node 
metastasis, tumor thickness, ulceration, mitotic index, necrosis, and presence of tumor-infiltrating lymphocytes. These findings mirror most of the findings from previous studies in Asia.

Neither BRAF mutation testing nor its inhibitor has been widely used in clinical management of melanoma cases in Indonesia. Up to now, our national health insurance program does not yet cover BRAF inhibitor as the therapy for melanoma. The patients were mostly treated by decarbazine. Therefore, there is no published study about the efficacy of BRAF inhibitors in Indonesian populations. Further studies are needed to address this issue. This study will become a foundation for pioneering the application of BRAF mutation detection for prognosis and therapy purposes in Indonesia. Information on the patients' mutation status can help predict the survival rates. The patients identified with the mutation may get benefits from BRAF inhibitor therapy. With the known clinicopathologic associations with this mutation, we can be more selective in which patients would likely benefit from BRAF mutation testing and inhibitor therapy. With further research, BRAF mutation testing and therapy can be more widely implemented in South-East Asia, especially Indonesia.

\section{Conclusion}

BRAF V600 mutations were found in 10\% of primary skin nodular melanoma cases in Yogyakarta and Central Java, lower than previous studies both among Asian and Caucasian populations. This low mutation prevalence and the unusual nodular subtype predominance suggest that melanoma among Javanese ethnic may have distinct clinicopathological characteristics from other Asian ethnicities. The presence of the BRAF V600 mutation is significantly associated with anatomic location and lymphovascular invasion. There is a need for further research using more advanced methods (such as nextgeneration sequencing), specifying the subtype of the BRAF V600 mutations, and investigating other mutations in the MAPK pathway, such as NRAS or KIT, in South East Asia, including Indonesia.

\section{Abbreviations}

DNA: Deoxyribonucleic acid; FFPE: Formalin-fixed paraffin-embedded; HRP: Horseradish peroxidase; MAPK: Mitogen-activated protein kinase; PCR: Polymerase chain reaction; TILs: Tumor-infiltrating lymphocytes

\section{Acknowledgements}

The authors want to thank Nur Eka Wiraditya for his assistance in laboratory works.

\section{About this supplement}

This article has been published as part of BMC Proceedings Volume 13 Supplement 11, 2019: Selected articles from the 3rd International Symposium on Congenital Anomaly and Developmental Biology 2019 (ISCADB 2019). The full contents of the supplement are available online at $h t t p s: / / b m c p r o c$. biomedcentral.com/articles/supplements/volume-13-supplement-11.

\section{Authors' contributions}

HTR designed the study and performed the analysis. HTR, MFP, and I wrote the manuscript. RPMA, NH, and BK contributed to the data collecting and analysis. All authors read and approved the final manuscript.

\section{Funding}

This work and publication cost of this article was funded by Faculty of Medicine, Public Health, and Nursing, Universitas Gadjah Mada.

\section{Availability of data and materials}

All data generated or analyzed during this study are included in the submission. The raw data are available from the corresponding author on reasonable request.

Ethics approval and consent to participate

This study protocol was reviewed and approved by the Medical and Health Research Ethics Committee of Faculty of Medicine, Public Health, and Nursing, Universitas Gadjah Mada.

\section{Consent for publication}

Not applicable.

\section{Competing interests}

The authors declare that they have no competing interests.

\section{Author details}

'Department of Anatomical Pathology, Faculty of Medicine, Public Health, and Nursing, Universitas Gadjah Mada/ Dr. Sardjito Hospital, Radiopoetro Building, 4th Floor, Farmako Street, Sekip Utara, Sinduadi, Mlati, Sleman, Yogyakarta 55281, Indonesia. ${ }^{2}$ Department of Anatomical Pathology, dr. Soeradji Tirtonegoro Hospital, Klaten, Central Java 57424, Indonesia.

Published: 16 December 2019

References

1. The Global Cancer Observatory. GLOBOCAN fact sheets: melanoma of skin. 2019.

2. Bartlett EK, Karakousis GC. Current staging and prognostic factors in melanoma. Surg Oncol Clin NA. 2018;24(2):215-27. Available from:. https:// doi.org/10.1016/j.soc.2014.12.001

3. Liu Y, Sheikh MS. Melanoma: molecular pathogenesis and theraupetic management. Mol Cell Pharmacol. 2015;6(3):228

4. Chang JW, Quek R, Hung C, Lu S, Ying A, Ho GF, et al. Sunrise in melanoma management : time to focus on melanoma burden in Asia. Asia Pacific J Clin Oncol. 2017:13:423-7.

5. Sheen Y, Liao Y, Liau J, Chu C. Prevalence of BRAF and NRAS mutations in cutaneous melanoma patients in Taiwan. J Formos Med Assoc. 2019;115(2): 121-7. Available from:. https://doi.org/10.1016/j.jfma.2015.02.001.

6. Yamazaki N, Tanaka R, Tsutsumida A, Namikawa K, Eguchi H, Omata W, et al. BRAF V600 mutations and pathological features in Japanese melanoma patients. Melanoma Res. 2015;25(1):9-14.

7. Jin SA, Chun SM, Choi YD, Kweon S-S, Jung ST, Shim HJ, et al. BRAF mutations and KIT aberrations and their clinicopathological correlation in 202 Korean melanomas. J Invest Dermatol. 2013;133(2):579-82.

8. Kang X, Zeng Y, Liang J, Li J, Ren D, Chai L, et al. Aberrations and clinical significance of BRAF in malignant melanoma: A series of 60 cases in Chinese Uyghur. Medicine (Baltimore). 2018;97(1):e9509.

9. Si L, Kong $Y, X u X$, Flaherty KT, Sheng X, Cui $C$, et al. Prevalence of BRAF V600E mutation in Chinese melanoma patients: Large scale analysis of BRAF and NRAS mutations in a 432-case cohort. Eur J Cancer. 2012;48(1):94-100.

10. Tjarta A, Kanokor M, Ueda M, Hamzah M, Cipto H. Rare case of melanoma studied for its histopathological features in Indonesia. Med I Indones. 2000; 9(2):93.

11. Pasaribu ET, Setiaji K, Rinonce HT, Azhar RY, Wahyono A, Pasaribu ET. Clinical and pathological profile of skin melanoma in Dr. Sardjito Hospital, Yogyakarta, Indonesia. Eur J Surg Oncol. 2019:e137. Available from. https:/ doi.org/10.1016/j.ejso.2018.10.466

12. Usman HA, Hernowo BSH, Tobing MDL, Hindritiani R. Result analysis of BRAF V600E gene mutation using molecular and immunohistochemistry detection in acral malignant melanoma. Asia Pacific J Cancer Care. 2018; 3((3):43. 
13. Mar V, Roberts H, Wolfe R, English DR, Kelly JW. Nodular melanoma: a distinct clinical entity and the largest contributor to melanoma deaths in Victoria, Australia. J Am Dermatol. 2012;68(4):568-75. Available from:. https:// doi.org/10.1016/j.jaad.2012.09.047.

14. Hendry S, Salgado R, Gevaert T, Russell PA, John T, Thapa B, et al. Assessing tumor infiltrating lymphocytes in solid tumors: a practical review for pathologists and proposal for a standardized method from the international Immuno-oncology biomarkers working group: part 2: TILs in melanoma, gastrointestinal tract carcinom. Adv Anat Pathol. 2017;24(6):311-35.

15. Can N, Taştekin E, Yalta TD, Süt N, Korkmaz S, Usta U, et al. BRAF V600 mutation profile of metastatic melanoma in the Thrace region of Turkey. Turkish J Pathol. 2018;34(2):134-42.

16. Ruiz-Garcia E, Matus-Santos JA, Alvarez-Avitia MA, Aguilar-Ponce JL, Fernandez-Figueroa E, Lopez-Camarillo C, et al. Frequency of BRAF V600E mutation in the Mexican population of patients with metastatic melanoma. J Glob Oncol. 2017:4:1-5.

17. Heppt MV, Siepmann T, Engel J, Schubert-fritschle G, Eckel R, Mirlach L, et al. Prognostic significance of BRAF and NRAS mutations in melanoma: a German study from routine care. BMC Cancer. 2017;17(536):1-12.

18. Lee J-H, Choi J-W, Kim Y-S. Frequencies of BRAF and NRAS mutations are different in histological types and sites of origin of cutaneous melanoma : a meta-analysis. Br J Dermatol. 2011;164:776-84.

19. Thomas NE, Edmiston SN, Alexander A, Groben PA, Parrish E, Kricker A, et al. Association between NRAS and BRAF mutational status and melanomaspecific survival among patients with higher-risk primary melanoma. JAMA Oncol. 2015;1(3):359-68.

20. Hugdahl E, Kalvenes MB, Puntervoll HE, Ladstein RG, Akslen LA. BRAF-V600E expression in primary nodular melanoma is associated with aggressive tumour features and reduced survival. Br J Cancer. 2016;1 14(7):801-8. Available from:. https://doi.org/10.1038/bjc.2016.44.

21. Inumaru JSS, Gordo KIF, Fraga Junior AC, Silva AMTC, Leal CBQS, Ayres FM, et al. Analysis of the BRAF V600E mutation in primary cutaneous melanoma. Genet Mol Res. 2014;13(2):2840-8.

22. Obadofin O, Badmos K, Orsi N, Bipin M, Rotimi O, Banjo A. Immunohistochemical analysis of BRAF (V600E) mutation and P16 expression in malignant melanoma in Lagos, Nigeria : a 10-year retrospective study. J Skin Cancer. 2019;2019:1628247.

23. Morita SY, Markovic SN. Molecular targets in melanoma: time for "ethnic personalization". Expert Rev Anticancer Ther. 2012;12(5):601-8.

24. Paluncic J, Kovacevic Z, Jansson PJ, Kalinowski D, Merlot AM, Huang ML, et al. Roads to melanoma : key pathways and emerging players in melanoma progression and oncogenic signaling. Biochim Biophys Acta. 2016;1863(4):77084. Available from:. https://doi.org/10.1016/j.bbamcr.2016.01.025.

25. Kong BY, Carlino MS, Menzies AM. Biology and treatment of BRAF mutant metastatic melanoma. Melanoma Manag. 2016;3(1):33-45.

26. Zhu M, Zhou L, Sadri N. Comparison of targeted next generation sequencing (NGS) versus isolated BRAF V600E analysis in patients with metastatic melanoma. Virchows Arch. 2018:473(3):371-7.

27. Cheng L, Lopez-beltran A, Massari F, Maclennan GT, Montironi R. Molecular testing for BRAF mutations to inform melanoma treatment decisions: a move toward precision medicine. Mod Pathol. 2018;31(1):24-38. Available from: https://doi.org/10.1038/modpathol.2017.104.

28. Aung PP, Mph DL, Kyle J, Ma F. Microvessel density, lymphovascular density, and lymphovascular invasion in primary cutaneous melanoma - correlation with histopathologic prognosticators and BRAF status. Hum Pathol. 2015;46(2):304-12. Available from:. https://doi.org/10. 1016/j.humpath.2014.11.006.

\section{Publisher's Note}

Springer Nature remains neutral with regard to jurisdictional claims in published maps and institutional affiliations.

Ready to submit your research? Choose BMC and benefit from:

- fast, convenient online submission

- thorough peer review by experienced researchers in your field

- rapid publication on acceptance

- support for research data, including large and complex data types

- gold Open Access which fosters wider collaboration and increased citations

- maximum visibility for your research: over $100 \mathrm{M}$ website views per year

At BMC, research is always in progress.

Learn more biomedcentral.com/submissions 